\title{
Acute respiratory illness in the community: Effect of family composition, smoking, and chronic symptoms
}

\author{
ARNOLD S. MONTO AND HELEN ROSS \\ From the Department of Epidemiology, School of Public Health, University of Michigan
}

SUMMARY Respiratory illness and infection was studied in the community of Tecumseh, Michigan, USA, during a six-year period. Acute illness was ascertained by making weekly telephone calls, and prevalent agents were identified by microbial isolation. Infection rates were determined serologically using blood specimens collected routinely at six monthly intervals from those reported to be ill. Illness rates were higher in the youngest children of families up to the age of three years than for the oldest children of the same ages. Above the age of three, the pattern was reversed. Among the adults, rates of illness were shown to relate not only to the presence, but also to the age of children in the home. Throughout this comparison, women were more likely to be ill than men in the same groups. Smoking in itself was not related to increased acute respiratory illnesses, but persons with symptoms of chronic bronchitis were found to have higher illness rates independently of whether they smoked.

Acute respiratory infections are the most common conditions affecting the American population (United States Public Health Service, 1973). They have thus far defied efforts at control and more knowledge of their incidence and aetiology is needed. To define factors involved in the occurrence of such illnesses in an ordinary community setting, a longitudinal study was carried out in Tecumseh, Michigan, USA (Monto et al., 1971; Monto and Cavallaro, 1971). Certain results have been described previously; among them were the observations that infant boys had the highest rates of acute illness, and that illness rates decreased as families got richer but increased as they became better educated (Monto and Ullman, 1974). In the current report further data on illness and infection in Tecumseh are presented. Of particular interest is the relationship of illnesses to cigarette smoking and symptoms of chronic bronchitis, and the influence of family composition on disease frequency.

\section{Methods}

RECRUITMENT AND SURVEILLANCE

The study of the Tecumseh community has been described in detail (Monto et al., 1971; Monto and
Ullman, 1974). The population of the study area was 10000 . Surveillance and viral isolation took place during a six-year period from 1966 to 1971 . After all dwelling units had been identified, households were systematically recruited, and information on family income and educational level of head of household and spouse was obtained directly from a representative of each family; $73.9 \%$ of those approached agreed to participate in the programme. The period of surveillance was one year, after which the household was replaced by a newly recruited family. Recruitment was carried out gradually, so a complete turnover did not occur. The aim throughout was to maintain a total of 1000 individuals on surveillance. Once within the programme, $86.3 \%$ of individuals continued to participate for 46 weeks or longer.

After recruitment, any acute illness in a family was reported. Weekly contacts were made by telephone, or in the few instances where the family did not have a telephone, by personal visit. In either case, the household respondent was asked if there had been any respiratory illness in the family during the previous week. Details of illnesses were obtained so that those that were respiratory could be identified and classified as belonging to one of five syndromes. After the initial report, the 
household was contacted regularly, and the respondent asked if the illness still persisted. If the illness had ended, the date it had finished was obtained. Data were also collected throughout on development of illness in other family members.

\section{MICROBIOLOGICAL METHODS}

Specimens for microbial isolation were collected within two days of onset from those in whom illness was reported. In all cases, a cotton swab was used to collect secretions from the oropharynx, and if nasal discharge was present an additional nasal swab was obtained. Material collected from one person was pooled in a single vial of veal infusion broth and taken to the laboratory on the same day. Specimens were inoculated into tubes of W1-38, primary rhesus monkey kidney and HL cells for isolation of the virus. Diphasic cultures were used for isolating the mycoplasma, and sheep blood agar plates to identify the haemolytic streptococci. Isolates were identified by standard procedures (Monto and Cavallaro, 1971).

Blood specimens were collected routinely from each family at the time of recruitment, after six months, and after one year (at the end of the study period). As recruitment and replacement of households was carried out continuously, these sera were collected all the year round (Monto and Lim, 1971). All specimens collected from a randomly-selected subset of households were tested to identify infection through detection of fourfold rises in antibody titre. Complement-fixation tests were run with respiratory syncytial (RS) virus and Mycoplasma pneumoniae antigens. Haemagglutination-inhibition (HI) tests were used for the type A and the type $B$ influenza strains prevalent in the community at the time of serum collection, and for parainfluenza types 1,2 , and 3 . It is known that cross-reactions are common among the parainfluenzaviruses and, therefore, for the analysis of these results, it was conservatively assumed that an increase in titre for more than one type represented a single infection (Monto, 1973). To obtain an approximate overall infection rate for individuals during their year of surveillance, data for the parainfluenzaviruses and from the four other serological tests were pooled by combining numerators (numbers of rises in titre) and denominators (number of persons studied) from the individual tests.

CLASSIFICATION OF SYMPTOMS OF COUGH AND SPUTUM PRODUCTIONS AND OF CIGARETTE SMOKING

During the last two years of the study adult participants were asked three times, at six-monthly intervals, using a modification of the Medical Research Council's questionnaire, to describe any symptoms of chronic cough and sputum they might have, and the number of cigarettes smoked daily. At the end of the surveillance year, the three reports obtained from each individual were summarised. The method used was to assign numerical designations to different levels of symptoms, or of cigarette use in the individual reports, and then to add the three to produce an index.

The usual presence of cough and sputum production for three months or more of the year has been accepted as the standard definition of chronic bronchitis and was so adopted in this study (Monto et al., 1975). Those reporting the symptoms but with insufficient persistence were classed as suspect bronchitics. In each of the three reports, suspect bronchitis was given a value of 1 , bronchitis a value of 2 , and no symptoms 0 . After the figures in three reports had been added together, those with a total of 0 to 2 were placed in bronchitis class 1 , those with 3 to 5 in bronchitis class 2 , and those with 6 (bronchitis on all three occasions) in class 3. Similarly those who, in a single report, did not report smoking cigarettes were given a value of 0 , those who smoked less than a pack a day were given 1, those who smoked at least a pack but less than a pack and a half a day were designate 2 , and those who smoked more than that amount were assigned 3. After summing all three reports, individuals with totals of 0 were placed in the non-smoking category, those with 1 to 3 in the light smoking category, those with 4 to 6 in the moderate smoking category, and those with 7 to 9 in the heavy smoking category.

\section{Results}

EFFECT OF FAMILY COMPOSITION ON

ILLNESS RATES

Age and sex have been shown to play an important role in determining the number of acute respiratory illnesses an individual may experience (Lidwell and $\mathrm{o}$ Sommerville, 1951; Dingle et al., 1964). In previously reported analyses of data from the Tecumseh community, as a child grew older he had $\underset{\mathrm{N}}{\mathrm{N}}$ fewer acute respiratory illnesses during the year, o ranging from a high of $6 \cdot 1$ in those younger than $N$ one year to 2.4 in those between 15 and 19 years $N$ of age (Monto and Ullman, 1974). Young boys had ${ }_{\sigma}^{\omega}$ higher rates of illness than girls until the age of three at which point the girls began to experience $\frac{0}{\mathbb{D}}$ more frequent illnesses. Other variables of family composition have now been examined to determine their relationship to illness. Among children, position in the family was as important as sex inष्ठ 
determining incidence of illness. Annual rates at various age levels were separately calculated for the oldest and the youngest children in the family; for the purposes of this analysis, an only child was considered to be the oldest child, which he later became as younger siblings were born. Figure 1 shows that the oldest child in the family had lower rates of illness up to the age of three than did a child of the same age who had older siblings.

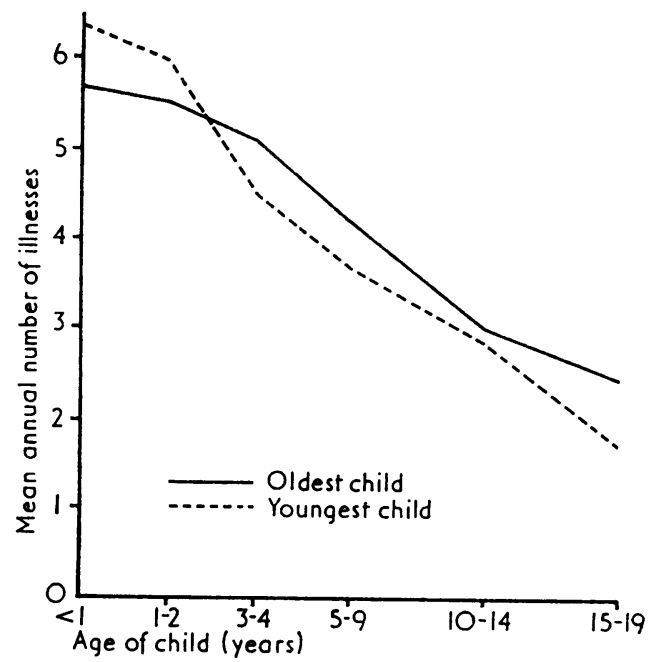

Fig. 1 Mean number of respiratory illnesses experienced by oldest and youngest children in the family.

This finding is consistent with the fact that these older siblings are known to be introducers of infection into the family. In contrast, the oldest child under the age of three is often the only child or has only very young siblings and thus does not have this type of exposure. However, from three years of age onwards, the oldest child consistently had higher rates of illness. By three, the oldest child is more mobile and becomes the trailblazer for the family, actually experiencing more illnesses than the youngest children, and this risk continues throughout childhood.

Family composition not only affected illness frequency in children, but also in parents. Among the familial variables which were significantly related to adults' incidence of respiratory disease were the presence and ages of children. Age of oldest child showed one of the best correlations. Here, as is usual, the correlation coefficient was greater for adult women who are more exposed to their children $(r=-0 \cdot 30)$, than for adult men $(r=-0 \cdot 21)$. Relationship of illness with age of oldest child for men and women is shown in Fig. 2,

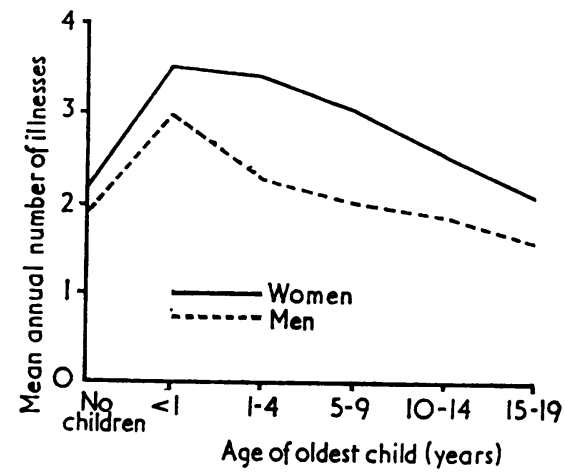

Fig. 2 Effect of age of oldest child in the family on number of respiratory illnesses experienced by the adults.

with the analysis restricted to adults of under 45 years. In each curve, on the far left is shown the annual illness frequency for persons without children. Interestingly, even this point is slightly higher for women. The presence of a child under one year of age produced a sharp increase in rates of illness for both parents. Thereafter, there was a gradual decline in the illness frequency experienced by the parents as the oldest children became older. Throughout, the rates for mothers remained considerably higher than that for fathers. By the time the oldest child had reached 10 to 14 years for the fathers and 15 to 19 years for the mothers, the parents' rates had fallen below that for adults without children in the home.

SEASONALITY OF RESPIRATORY VIRUSES AND THEIR ASSOCIATION WITH REPORTED SYMPTOMS

It has been noted that syndromes produced by the many respiratory viruses overlap to such an extent that in the individual case it was impossible to tell which agent was causing a particular illness (Parrott et al., 1963; Evans, 1967). However, in Tecumseh, when illnesses were examined in the aggregate, definite patterns in frequency of symptoms associated with certain viruses could be detected. Figure 3 shows the types of symptoms in individuals from whom five different kinds of viruses were isolated; symptoms associated with isolation of haemolytic streptococci are shown for comparison. In each case the bar depicts the percentage of individuals from whom the particular agent was isolated who exhibited the symptom. Coryza was pronounced with all viruses, particularly with rhinoviruses the principal cause of common colds, with from $70 \%$ to $90 \%$ of individuals having the symptom. It was at lowest frequency in persons 


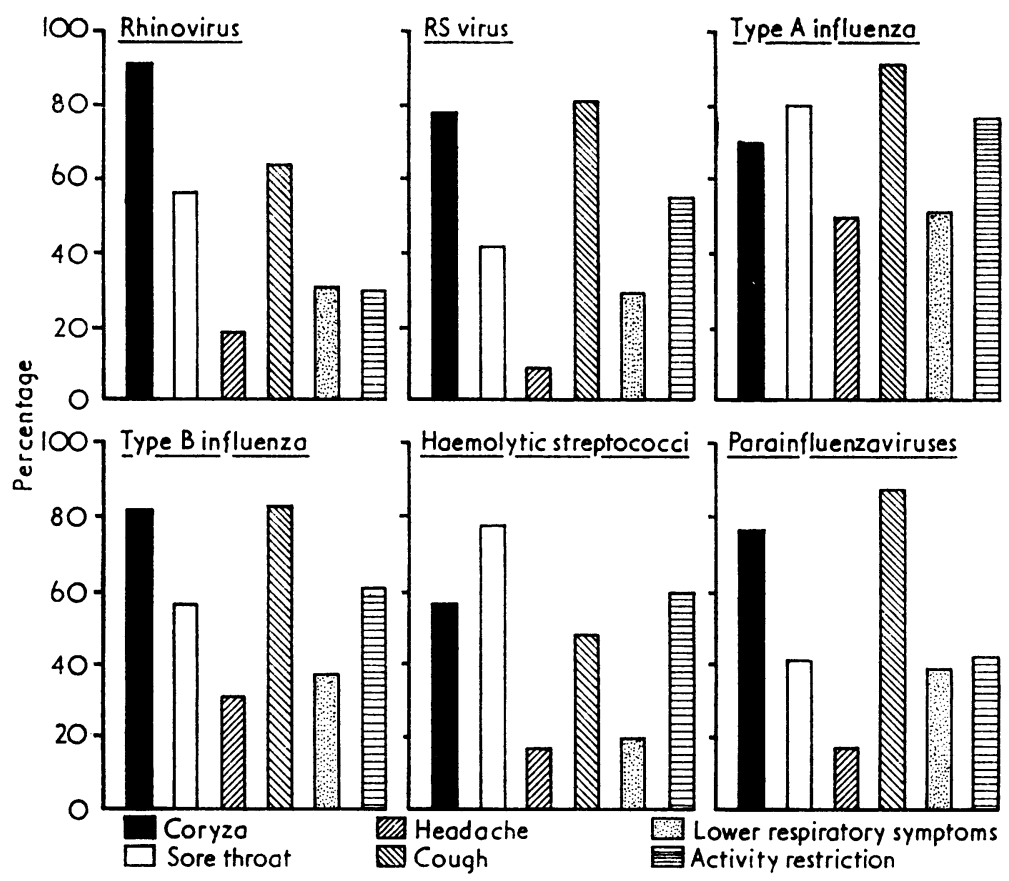

Fig. 3 Characteristics of illnesses associated with isolation of viruses and haemolytic streptcoocci: percentage of those infected experiencing five symptoms and activity restriction.

with streptococcal isolation, but it still appeared in more than half of cases. Here, as expected, sore throat predominated. As certain parainfluenzaviruses cause croup in small children, it might be thought that they would be associated with hoarseness in the total population. In fact, it was found that type $\mathbf{A}$ influenza was the agent most associated with this symptom. While non-productive cough was common to all the viruses, the lower respiratory symptoms of productive cough, pain on respiration, and/or wheezy breathing proved somewhat better in discriminating between the agents. Restriction of daily activity was an important additional factor. It was very frequent with influenza A, somewhat less common with type B influenza, haemolytic streptococci, and respiratory syncytial (RS) virus, and least common with rhinoviruses. Taken together, it can be seen that type A influenzaassociated illnesses were of the greatest severity, with high incidence of various symptoms. Type B influenza was somewhat less severe. Illnesses associated with haemolytic streptococci, parainfluenza, and RS viruses were intermediate, with varying characteristics. The mildest diseases in general were those with isolation of the rhinoviruses. Thus, clear differences between patterns of illness associated with the different agents could be found in spite of the considerable overlap.

To help determine the cause of a particular illness it is useful to study the seasonal changes in prevalence $\mathbb{Q}$ of the viruses. Figure 4 gives a summary of the $\overrightarrow{\vec{\sigma}}$ calendar months of isolation of four types of 3 viruses during the six years of the study. For purposes of this figure, the type $A$ and $B$ influenza? were considered together because they had a similar $\bar{\infty}$ pattern. The results are shown as a percentage $\stackrel{\rho}{\zeta}$ distribution of isolates in the various months. As $\sigma$ noted in previous studies, rhinoviruses were by far the most important agents in terms of number of $\delta$ isolates, and they were recovered in all months of the year (Monto and Ullman, 1974), although 0 more than $20 \%$ of isolations were made in September. This resulted from the burst of illnesses, mainly rhinovirus in aetiology, which followed the return of children to school; such an event was. seen in Tecumseh regularly in all but one year of the $N$ study. Interestingly, frequency of isolation decreased N steadily until January and then increased to May. $O$ Other agents-such as the difficult to isolate coronaviruses-are probably important in filling in $\frac{0}{\Phi}$ for the rhinoviruses in midwinter as the aetiological $\stackrel{\oplus}{\rightarrow}$ agents of colds. The late autumn and early winter 0 were the main periods for the parainfluenzaviruses, $\overrightarrow{0}$ with $72.5 \%$ of isolations being made from 

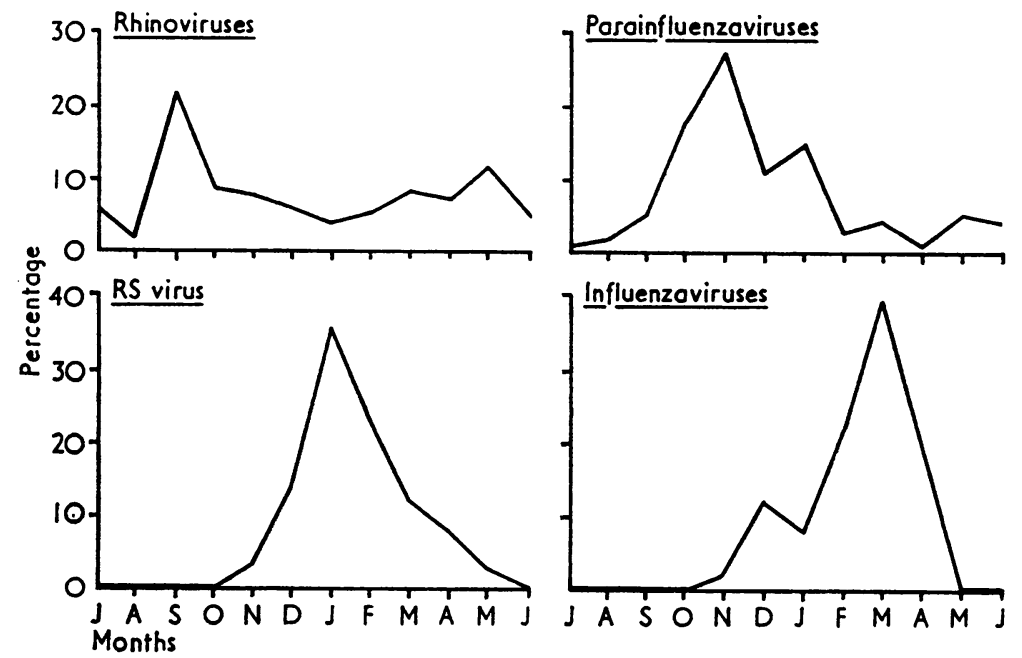

Fig. 4 Seasonality of respiratory agents: proportion isolated in each calendar month during six years of study.

October to January. Only sporadic isolates were made at other times; these were mainly type 3 , with types 1 and 2 occurring almost exclusively during the peak months. Unlike these viruses, RS virus was isolated for only a limited period during each year of the study. When these were added together for the six-year study period, most were found to have been recovered in midwinter. In contrast, influenza, better known for its epidemic behaviour, occurred somewhat later in winter or early spring. Not shown in the figure is the pattern of recovery of haemolytic streptococci. While these bacteria were isolated in all months, more than $57 \%$ were made from January to April, the expected distribution in the northern United States. Thus, considering the marked seasonal fluctuation of some of the agents it is possible to narrow down the great variety of viruses that might be causing an illness by the time it occurs.

\section{EFFECT OF SMOKING ON ILLNESS RATES}

During the last two years of the study, adult participants were asked three times during their year on surveillance to state the quantity of cigarettes smoked, if any, and to describe any chronic symptoms of cough and sputum production that they might have. Both amount smoked and degree of cough and sputum were divided into several graded categories based on the average of the three responses. The light smoking category indicated that the individual usually smoked during the course of the year, but less than one pack a day. Moderate smoking indicated that 20 to 29 cigarettes a day was the usual level of smoking, and heavy smoking 30 or more cigarettes a day. For cough and sputum production, category 0 included individuals without these symptoms or reporting their existence on only one occasion. To be placed in category 1 , an individual reported symptoms sufficient to be defined as suspect or probably chronic bronchitis on fewer than three occasions; category 2 was reserved for those diagnosed by symptoms as having chronic bronchitis on all three determinations. Table 1 gives the mean rates of all acute respiratory illnesses and of those illnesses with lower respiratory symptoms at different levels of smoking. There was no clear relationship of amount smoked with frequency of acute illnesses in either men or women. In fact, among the men, rates of total illnesses actually fell as amount of smoking increased, but rebounded at the heavy, or 30 cigarette a day, level. None of these differences was statistically significant. A different situation was found when the acute illness rates were instead divided by chronic bronchitis status, as shown in Table 2. Among the men, there was a greater incidence of acute illnesses as severity of chronic symptoms increased. Among the women, those with chronic symptoms were also found to experience somewhat more acute illnesses than those without, but the increase was not sequential. The differences between the mean acute illness rates at cough and sputum status 0 and 1 were statistically significant ( $P<0.05$ for men, $P<0.01$ for women) for lower respiratory illnesses, but not for total respiratory illnesses.

The association of acute illnesses with bronchitis but not with cigarette usage is of interest, as it is well known that cough and sputum production are strongly related to smoking. To explore these 
Table 1 Relationship of cigarette smoking to annual incidence of all acute respiratory illnesses and those with lower respiratory symptoms

\begin{tabular}{|c|c|c|c|c|c|c|c|c|c|c|}
\hline \multirow{3}{*}{ Smoking status } & \multicolumn{5}{|l|}{ Men } & \multicolumn{5}{|c|}{ Women } \\
\hline & \multirow[t]{2}{*}{ No. } & \multicolumn{2}{|c|}{ Total illnesses } & \multicolumn{2}{|c|}{ Lower illnesses } & \multirow[t]{2}{*}{ No. } & \multicolumn{2}{|c|}{ Total illnesses } & \multicolumn{2}{|c|}{ Lower illnesses } \\
\hline & & Mean & $(S D)$ & Mean & $(S D)$ & & Mean & $(S D)$ & Mean & $(S D)$ \\
\hline $\begin{array}{l}\text { None } \\
\text { Light } \\
\text { Moderate } \\
\text { Heavy }\end{array}$ & $\begin{array}{r}120 \\
26 \\
29 \\
37\end{array}$ & $\begin{array}{l}1 \cdot 8 \\
1 \cdot 7 \\
1 \cdot 1 \\
1 \cdot 6\end{array}$ & $\begin{array}{l}(1 \cdot 7) \\
(1 \cdot 4) \\
(1 \cdot 1) \\
(1 \cdot 4)\end{array}$ & $\begin{array}{l}0.6 \\
0.9 \\
0.4 \\
1.0\end{array}$ & $\begin{array}{l}(0 \cdot 8) \\
(1 \cdot 1) \\
(0 \cdot 6) \\
(1 \cdot 1)\end{array}$ & $\begin{array}{r}195 \\
32 \\
32 \\
25\end{array}$ & $\begin{array}{l}2 \cdot 1 \\
1 \cdot 8 \\
2 \cdot 1 \\
2 \cdot 0\end{array}$ & $\begin{array}{l}(1 \cdot 8) \\
(1 \cdot 6) \\
(1 \cdot 5) \\
(1 \cdot 6)\end{array}$ & $\begin{array}{l}0 \cdot 8 \\
0 \cdot 9 \\
1 \cdot 1 \\
1 \cdot 1\end{array}$ & $\begin{array}{l}(1 \cdot 0) \\
(1 \cdot 1) \\
(1 \cdot 2) \\
(1 \cdot 2)\end{array}$ \\
\hline
\end{tabular}

Table 2 Relationship of chronic bronchitis to annual incidence of all respiratory illnesses and those with lower respiratory symptoms

\begin{tabular}{|c|c|c|c|c|c|c|c|c|c|c|}
\hline \multirow{3}{*}{ Cough und sputum } & \multicolumn{5}{|l|}{ Men } & \multicolumn{5}{|c|}{ Women } \\
\hline & \multirow[t]{2}{*}{ No. } & \multicolumn{2}{|c|}{ Total illnesses } & \multicolumn{2}{|c|}{ Lower illnesses } & \multirow[t]{2}{*}{ No. } & \multicolumn{2}{|c|}{ Total illnesses } & \multicolumn{2}{|c|}{ Lower illnesses } \\
\hline & & Mean & $(S D)$ & Mean & $(S D)$ & & Mean & (SD) & Mean & (SD) \\
\hline $\begin{array}{l}0 \\
1 \\
2\end{array}$ & $\begin{array}{r}166 \\
36 \\
10\end{array}$ & $\begin{array}{l}1 \cdot 6 \\
1.9 \\
2 \cdot 3\end{array}$ & $\begin{array}{l}(1 \cdot 5) \\
(1 \cdot 5) \\
(1 \cdot 8)\end{array}$ & $\begin{array}{l}0.5 \\
1.1 \\
1.4\end{array}$ & $\begin{array}{l}(0 \cdot 8) \\
(1 \cdot 2) \\
(1 \cdot 1)\end{array}$ & $\begin{array}{r}231 \\
45 \\
8\end{array}$ & $\begin{array}{l}2 \cdot 0 \\
2 \cdot 4 \\
2 \cdot 2\end{array}$ & $\begin{array}{l}(1 \cdot 7) \\
(1 \cdot 9) \\
(2 \cdot 0)\end{array}$ & $\begin{array}{l}0.8 \\
1.4 \\
1.2\end{array}$ & $\begin{array}{l}(1 \cdot 0) \\
(1 \cdot 3) \\
(0 \cdot 8)\end{array}$ \\
\hline
\end{tabular}

relationships further, the acute illness rates were calculated for cough and sputum categories while controlling for cigarette smoking. As shown in Table 3, combination of groups was required for this analysis because of numbers involved. For men and women smokers and non-smokers, frequency of acute illnesses, both total and with lower respiratory symptoms was higher in individuals with history of chronic cough and sputum production than those without such a history. The differences were statistically significant in women for lower respiratory illnesses $(\mathrm{P}<0.05$ in smokers and non-smokers) and in men who smoked ( $P<0.01$ for lower illnesses, $P<0.05$ for total illnesses); taken together, these patterns suggest that smoking does not directly lead to more acute respiratory illnesses, but that those with symptoms of chronic bronchitis, which in itself is associated with cigarette smoking, have higher acute illness rates. Whether this indicates that respiratory infection has a separate role in the pathogenesis of chronic bronchitis cannot yet be determined.
EDUCATION AND INCOME-DIFFERENCES IN ILLNESS AND INFECTION RATES

It was previously shown in Tecumseh the reported rates of respiratory illness decreased families got richer, but increased with educationat level of head of household (Monto and Ullmas 1974). The relationship with income was easily explained by crowding and other factors associated with both low income and increased transmission $\stackrel{\mathbb{Q}}{\mathcal{Q}}$ of infection. However, the relationship with $\overrightarrow{\vec{P}}$ education appears to be more complex. It was $\frac{3}{3}$ claimed that those with higher levels of education $כ$ would possibly perceive symptoms as representing a respiratory illness which others, who were less educated, would not. This would imply that the $\stackrel{\odot}{?}$ ratio of symptomatic to asymptomatic infections varied with educational level. To evaluate this 3 . relationship the actual rates of infection for four different groups of respiratory viruses and $M$. pneumoniae were determined serologically by 0 identification of rise in antibody titre. The grouped infection rates are shown in Table $4 \frac{7}{0}$ divided by family income together with the

Table 3 Annual incidence of all acute respiratory illness and those with lower respiratory symptoms in cigarette smokers and non-smokers of differing levels of cough and sputum

\begin{tabular}{|c|c|c|c|c|c|c|c|c|c|c|c|}
\hline \multirow{3}{*}{ Smoking status } & \multirow{3}{*}{ Cough and sputum } & \multicolumn{5}{|c|}{ Men } & \multicolumn{5}{|c|}{ Women } \\
\hline & & \multirow[t]{2}{*}{ No. } & \multicolumn{2}{|c|}{ Total illnesses } & \multicolumn{2}{|c|}{ Lower illnesses } & \multirow[t]{2}{*}{ No. } & \multicolumn{2}{|c|}{ Total illnesses } & \multicolumn{2}{|c|}{ Lower illnesses } \\
\hline & & & Mean & $(S D)$ & Mean & $(S D)$ & & Mean & $(S D)$ & Mean & (SD) \\
\hline Non-smokers & $\begin{array}{l}0 \\
1 \text { and } 2\end{array}$ & $\begin{array}{r}108 \\
12\end{array}$ & $\begin{array}{l}1 \cdot 7 \\
2 \cdot 1\end{array}$ & $\begin{array}{l}(1 \cdot 6) \\
(1 \cdot 8)\end{array}$ & $\begin{array}{l}0.5 \\
0.9\end{array}$ & $\begin{array}{l}(0 \cdot 8) \\
(1 \cdot 0)\end{array}$ & $\begin{array}{r}170 \\
25\end{array}$ & $\begin{array}{l}2 \cdot 1 \\
2 \cdot 7\end{array}$ & $(1 \cdot 7)$ & $\begin{array}{l}0.7 \\
1.4\end{array}$ & $\begin{array}{l}(0 \cdot 9) \\
(1 \cdot 3)\end{array}$ \\
\hline Smokers & 1 and 2 & $\begin{array}{l}58 \\
34\end{array}$ & $\begin{array}{l}1 \cdot 2 \\
1 \cdot 9\end{array}$ & $\begin{array}{l}(1 \cdot 1) \\
(1 \cdot 5)\end{array}$ & $\begin{array}{l}0.5 \\
1 \cdot 3\end{array}$ & $\begin{array}{l}(0 \cdot 7) \\
(1 \cdot 2)\end{array}$ & $\begin{array}{l}61 \\
28\end{array}$ & $\begin{array}{l}1 \cdot 9 \\
2 \cdot 2\end{array}$ & $\begin{array}{l}(1 \cdot 5) \\
(1 \cdot 6)\end{array}$ & $\begin{array}{l}0.9 \\
1.4\end{array}$ & $\begin{array}{l}(1 \cdot 1) \\
(1 \cdot 2)\end{array}$ \\
\hline
\end{tabular}


previously reported actual rates of illness. The relationship of illnesses and infection with income level was similar; as the number of respiratory illnesses reported each year decreased with increase in income, so did the rates of infection for the agents.

Table 4 Relationship of family income to annual rate of respiratory illness and infection

\begin{tabular}{lclll}
\hline $\begin{array}{l}\text { Income range } \\
\text { ( } \$)\end{array}$ & \multicolumn{2}{l}{ Illness results } & \multicolumn{2}{l}{ Infection results } \\
\cline { 2 - 5 } & $\begin{array}{l}\text { No. in } \\
\text { group }\end{array}$ & $\begin{array}{l}\text { Illness } \\
\text { rates }\end{array}$ & $\begin{array}{l}\text { Rises in } \\
\text { titre }\end{array}$ & $\%$ \\
\hline$<4999$ & 185 & $3 \cdot 8$ & $77 / 499 *$ & $15 \cdot 4$ \\
$5000-6999$ & 603 & $3 \cdot 4$ & $198 / 1515$ & $13 \cdot 1$ \\
$7000-9999$ & 1504 & $3 \cdot 2$ & $459 / 3309$ & $13 \cdot 9$ \\
$10000-14999$ & 969 & $2 \cdot 8$ & $242 / 1910$ & $12 \cdot 7$ \\
$>15000$ & 371 & $2 \cdot 7$ & $97 / 784$ & $12 \cdot 4$ \\
\hline
\end{tabular}

*Grouped results for five agents in dicating rises in titre per number tested.

Infection rates were similarly divided by educational level; the results are shown in Table 5, with the appropriate illness rates included for reference. As educational levels increased, the infection rates did not increase as the illness rates had done. In fact instead of going up, the infection rates remained rather flat and then went down at the college level. These findings confirm the suggestion that the relationship of education with illness is based principally on differences in what different individuals perceive to be an illness.

Table 5 Relationship of education of head of household to annual rate of respiratory illness and infection

\begin{tabular}{lllll}
\hline Education level & \multicolumn{2}{l}{ Illness results } & \multicolumn{2}{l}{ Infection results } \\
\cline { 2 - 5 } & $\begin{array}{l}\text { No. in } \\
\text { group }\end{array}$ & $\begin{array}{l}\text { Illness } \\
\text { rates }\end{array}$ & $\begin{array}{l}\text { Rises } \text { in } \\
\text { titre }\end{array}$ & $\%$ \\
\hline Elementary school & & & & \\
Only & 376 & $2 \cdot 6$ & $111 / 810^{*}$ & $13 \cdot 7$ \\
Some high school & 672 & $2 \cdot 7$ & $219 / 1629$ & 13.4 \\
Finished high school & 1646 & $3 \cdot 2$ & $477 / 3436$ & 13.9 \\
Some college & 447 & $3 \cdot 5$ & $129 / 992$ & 13.0 \\
Finished college & 491 & 3.4 & $137 / 1150$ & 11.9 \\
\hline
\end{tabular}

*Grouped results for five agents indicating rises in titre per number tested.

\section{Discussion}

Many interrelated factors help to determine how often an individual will experience acute respiratory illness, but the main one is age. As shown previously in Tecumseh, infants experience the highest infection rates (Monto and Ullman, 1974). These rates then decrease steadily throughout life except for a slight increase in the 20 to 29 -year age group. The increase suggested the role that family composition plays in illness, since it is during this decade that young adults, in starting families, begin to be exposed to their small children. This environmental factor, presence of children in the home, was further investigated. The importance of children in producing infections in their parents was clearly demonstrated by the relationship of the adult's illness rates to the age of children in the home. As indicated in the Paddington study, it would be expected that younger children, who experience frequent infections because of high relative susceptibility, would transmit the agents to their parents (Brimblecombe et al., 1958). The higher rates in women can be explained by the closer contact mothers typically have with their children. However, the sex differential was also observed in adults without children so other factors must play a role. This situation is not unprecedented, and in fact, falls into the pattern seen with morbidity in general, with women having the higher frequency of illness (Wilder and Rivers, 1969).

It would seem that smoking, through its known effects on ciliary activity and other local protective mechanisms, should produce an increase in frequency of acute respiratory illness, but reports disagree on whether this really is the case. Among students, visits to the health service for respiratory illnesses were significantly more common for smokers than non-smokers (Peters and Ferris, 1967). However, other studies suggested that, if differences existed, it was not in overall frequency of illness but rather in symptoms or severity (Buck, 1956). Notably, in the Cleveland family study, colds occurred at the same rate in all groups, but cough was more commonly reported among the smokers (Boake, 1956). Subsequently the same features were observed in colds of rhinovirus aetiology (Gwaltney et al., 1967). The findings in Tecumseh support the concept that smoking in itself does not increase susceptibility to respiratory infection. However, the fact that the presence of even mild or transient symptoms of chronic bronchitis was associated with more frequent acute respiratory illnesses suggests a more important relationship, namely that these acute illnesses may be somehow involved in the development of chronic lung disease. It has already been found that those with established chronic bronchitis have more viral respiratory illnesses and infection than healthy individuals, so that confirmatory findings in persons with earlier or transient symptoms may indicate that the relationship reflects a role of infection in pathogenesis.

The observation that income and education have opposite effects on frequency of acute illness was a surprise in view of the fact that the two socioeconomic variables are highly correlated. The basis for these findings was explored by testing sera 
for change in antibody titre against respiratory agents, as a general indicator of the rate of infection. It has been noted repeatedly that the recognition of the existence of disease varies in different groups of people. Mechanisms may involve varying threshold levels for actual perception of complaints, as well as differences in recognition that minor symptoms, when perceived, represent an illness. These mechanisms must relate closely to education level since it was here that the reversal in trend for illness as opposed to infection occurred. All in all, the results are a dramatic demonstration of the basic distinction between illness and infection.

Understanding the main determinants of frequency of acute respiratory illness is a first step towards prevention of these infections. Since a variety of viruses are involved, priorities are being established for development of vaccines and other specific methods of control. Rhinoviruses are responsible for more than one-third of the respiratory infections of known aetiology and these agents would thus seem worthy of attention (Fox et al., 1975). However, because of certain problems, especially multiplicity of serotypes, it has seemed to some that prophylactic measures are not currently feasible. Recent epidemiological and laboratory data have suggested that this may not be the case for rhinoviruses, and similar optimism may be in order for other important agents as well. Certainly it would seem that acute respiratory infections are of such a major impact on the population that all avenues for control should be explored.

Portions of this work were supported by a grant (HL 13867) and a contract (PH 43-66-462) from the National Institutes of Health, Bethseda, Maryland, USA.

Reprints from A. S. Monto, Department of Epidemiology, School of Public Health, University of Michigan, Ann Arbor, Michigan 48109, USA.

\section{References}

Boake, W. C. (1956). A study of illnesses in a group of Cleveland families. XVIII. Tobacco smoking and respiratory infections. New England Journal of Medicine, 259, 1245-1249.

Brimblecombe, F. S. W., Cruickshank, R., Masters, P. L., Reid, D. D., and Stewart, G. T. (1958). Family studies of respiratory infections. British Medical Journal, 1, 119-128.

Buck, C. (1956). Acute upper respiratory infections in families. American Journal of Hygiene, 63, 1-12.
Dingle, J. H., Badger, G. F., and Jordan, W. S., Jr $\varnothing$ (1964). Illness in the Home: A study of 25000 Illnesses 3 in a Group of Cleveland Families. Case Western $\stackrel{\mathbb{Q}}{\triangle}$ Reserve University Press: Cleveland.

Evans, A. S. (1967). Clinical syndromes in adults caused $\vec{F}$ by respiratory infection. Medical Clinics of North America, 51, 803-818.

Fox, J. P., Cooney, M. K., and Hall, C. E. (1975). $\frac{\overline{\bar{D}}}{\bar{D}}$ The Seattle virus watch. V. Epidemiologic observa- $\frac{\vec{D}}{\vec{D}}$ tions of rhinovirus infections, 1965-1969, in families $\stackrel{\mathbb{Q}}{2}$ with young children. American Journal of Epidemiology, \& 101, 122-143.

Gwaltney, J. M., Jr, Hendley, J. O., Simon, G., and $\vec{\circ}$ Jordan, W. S., Jr (1967). Rhinovirus infections in an $\overrightarrow{\vec{\omega}}$ industrial population. II. Characteristics of illness and $\stackrel{\sigma}{\omega}$ antibody response. Journal of the American Medical $\overparen{D}$ Association, 202, 494-500.

Lidwell, O. M., and Sommerville, T. (1951). Observations $\dot{\omega}$ on the incidence and distribution of the common cold in a rural community during 1948 and 1949. Journal ? of Hygiene, 49, 365-381.

Monto, A. S. (1973). The Tecumseh study of respiratory illness. V. Patterns of infection with the parainfluenza- $\triangle$ viruses. American Journal of Epidemiology, 97, 338-348.

Monto, A. S., and Cavallaro, J. J. (1971). The Tecumseh study of respiratory illnesses. II. Patterns of occurrence of infection with respiratory pathogens, 1965-1969. American Journal of Epidemiology, 94, 280-289.

Monto, A. S., Higgins, M. W., and Ross, H. W. (1975 . The Tecumseh study of respiratory illness. VIIL Acute infection in chronic respiratory disease and comparison groups. American Review of Respiratory Diseases, 111, 27-36.

Monto, A. S., and Lim, S. K. (1971). The Tecumseh study of respiratory illness. III. Incidence and periodicity of respiratory syncytial and Mycoplasma pneumoniae infections. American Journal of Epidemiology, 94, 290-301.

Monto, A. S., Napier, J. A., and Metzner, H. L. (1971). The Tecumseh study of respiratory illnesses. I. Plan of study and observations on syndromes of acute respiratory disease. American Journal of Epidemiology, 94, 269-279.

Monto, A. S., and Ullman, B. M. (1974). Acute respiratory illness in an American community: the Tecumseh study. Journal of the American Medical Association, 227, 164-169.

Parrott, R. H., Vargosko, A. J., Kim, H. W., and Chanock, R. M. (1963). Clinical syndromes among children. American Review of Respiratory Diseases, 88, 73-76.

Peters, J. M., and Ferris, B. G., Jr (1967). Smoking and morbidity in a college-age group. American Review of $O$ Respiratory Diseases, 95, 783-789.

United States Public Health Service (1973). Current 0 Estimates from the Health Interview Survey, United 0 States (1971), Series 10, No. 79. US Department of Health, Education and Welfare.

Wilder, C. S., and Rivers, C. W. (1969). Current Estimates From the Health Interview Survey, Public Health Service publication No. 1000, Series 10 , No. 52. US Government Printing Office: Washington DC.

\section{.}

